\title{
Phobias and Gender- A Case Study on Engineering Students
} Sankara Pitchaiah Podila* ,Nazia Sultana**

${ }^{*}$ Psychologist and Professor of Geology, Acharya Nagarjuna University, Andhra Pradesh, India

${ }^{* *}$ Research Scholar, Department of Geology, Acharya Nagarjuna University, Andhra Pradesh, India

*Corresponding author email-lifeskillssankar@gmail.com

\section{ABSTRACT}

Fears and phobias are common in the student community. The present study was observed some of the specific phobias- Exam phobia, Acrophobia, Hemophobia, Achluophobia, Hodophobia, Zoophobia and Oneirophobia in engineering students with reference to gender. A total of 460 students studying in four Engineering colleges, located in Guntur and Prakasam districts was selected, out of which 294 are male and 166 are female. The study found that all the examined phobias were high in female students, particularly, Exam (50.60\%) and Zoophobia (39.16\%) are very high in female and compared to male (42.52\% and $13.27 \%)$.

Keywords: Specific Phobias, Therapies, Engineering Students, Gender

\section{INTRODUCTION}

A phobia is a type of anxiety disorder, defined by a persistent and excessive fear of an object or situation. Typically results in a rapid onset of fear and are present for more than six months (American Psychiatric Association, 2013). Different specific phobias, namely Exam phobia, Acrophobia, Hemophobia, Achluophobia, Hodophobia, Zoophobia and Oneirophobia are present in students. Fears and phobias are common in students. They have a serious impact on student academic achievement and well being. Phobias are irrational, that leads to avoidance of the phobia situation or object which in turn increases the severity of the phobia. Sufiana and Farhat (2015) found that the phobia of examination affects the academic performance of the students in the examination and they could not perform according to their knowledge due to a phobia of examination. Acrophobia is an irrational fear of heights. Acrophobic behavior typically involves the avoidance of a variety of situations, including stairs, terraces, apartments and offices located in high buildings, bridges, elevators and plane trips (Menzies, 1997). Hemophobia is an abnormal and persistent fear of blood, also called a blood injury phobia. Sufferers of this very common phobia dread the sight of their own blood, the sight of the blood of another person or an animal (https://www.medicinenet.com). Achluophobia is the scientific term for fear of the dark (https://www.allhealthsite.com).

Hodophobia is an irrational fear, or phobia, of travel (Ronald, 2010). Some people are afraid only of specific methods of transportation, such as planes or trains, while others fear all types of trips (https://www.verywellmind.com). Zoophobia or animal phobia is a class of specific phobias of a particular animal (Fodor and Gaynor, 2004) or an irrational fear or even simply dislike of any non-human animals. Oneirophobia is the fear of nightmares. 
Various studies were carried out on specific phobias (Ollendick et al., 2010; https://www. verywellmind.com/; Curtis et al., 1998; de OliveiraSouza 2018; Naveed et al., 2015; Carleton 2016; Garcia 2017 Pull 2008 and Singh and Singh 2016).

\section{METHODOLOGY}

A total of 460 students studying in four Engineering colleges, located in Guntur and Prakasam districts was selected, out of which 294 are male and 166 are female. Students were assembled in a classroom of the respective institutions and asked them to give their response to a question-"Do you have any specific fear/phobia?" The purpose of the study and the details regarding the phobia were explained in their mother tongue. The response was analyzed using statistical analysis. Percent variation and correlation studies are presented under results and discussion between the male and female students.

\section{RESULTS AND DISCUSSION}

Various phobias were studied with reference to gender and the results are incorporated in this section. Number of students with specific phobias was shown in table 1 and the percentages were given in table 2 .

TABLE 1

STUDENT'S WITH SPECIFIC PHOBIAS

\begin{tabular}{|l|c|c|c|}
\hline Phobias & Male & Female & Total \\
\hline Exam phobia & 125 & 84 & 209 \\
\hline Acrophobia & 44 & 28 & 72 \\
\hline Hemophobia & 24 & 25 & 49 \\
\hline Achluophobia & 25 & 26 & 51 \\
\hline Hodophobia & 11 & 12 & 23 \\
\hline Zoophobia & 39 & 65 & 104 \\
\hline Oneirophobia & 41 & 28 & 69 \\
\hline Total & $\mathbf{3 0 9}$ & $\mathbf{2 6 8}$ & $\mathbf{5 7 7}$ \\
\hline
\end{tabular}

\section{Comparative Study}

Compared to the males (42.52\%), high percent of female students $(50.60 \%)$ expressed exam phobia. Similarly, Zoophobia is high in female (39.16\%) than male (13.27\%). Though the difference is percentage is less compared to exam and zoophobia all other examined phobias are high female students (Figure 2). 


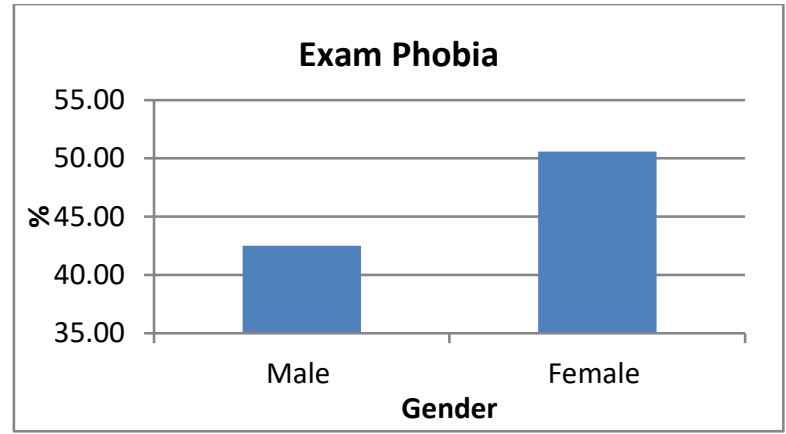

(a)

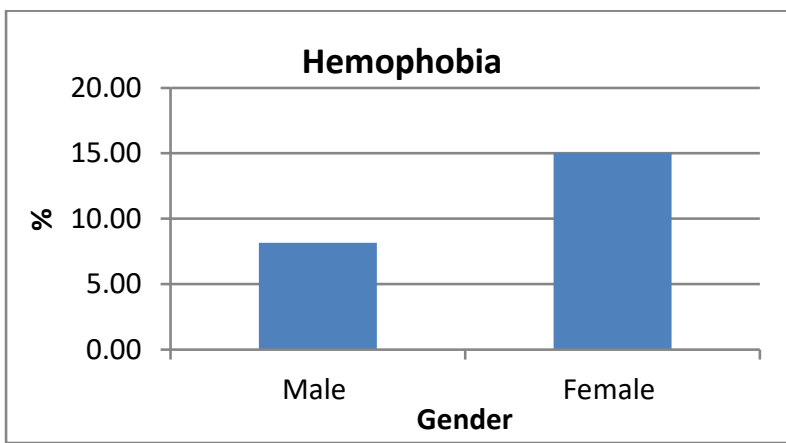

(c)

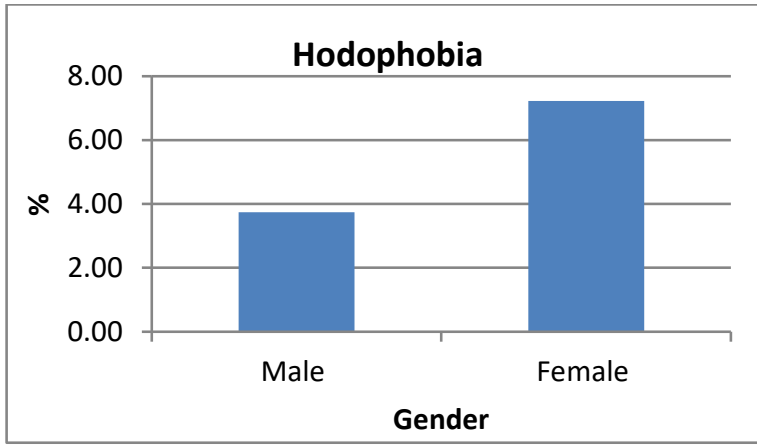

(e)

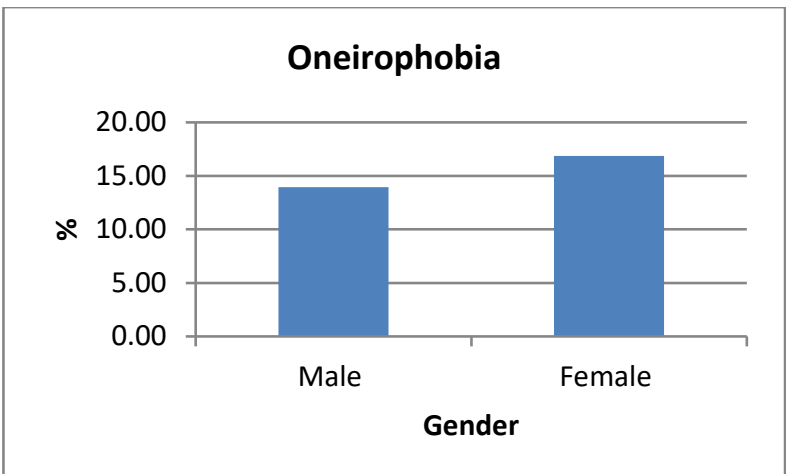

(g)

Figure 1 Phobias and Gender

\section{Treatment}

It is important to remember that the Phobias are common and you are not alone. At the

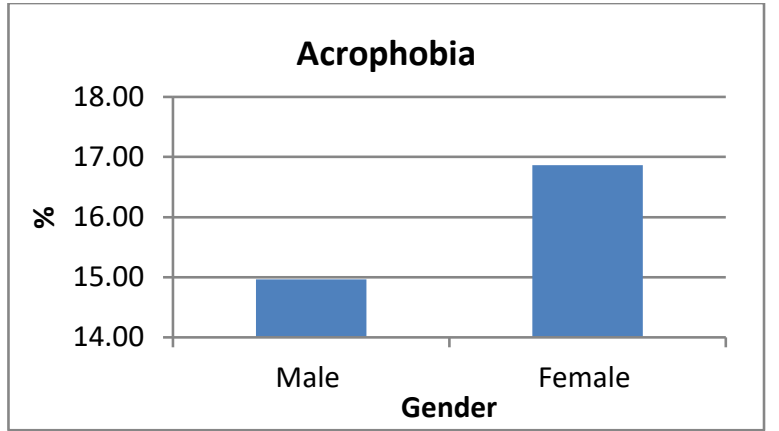

(b)

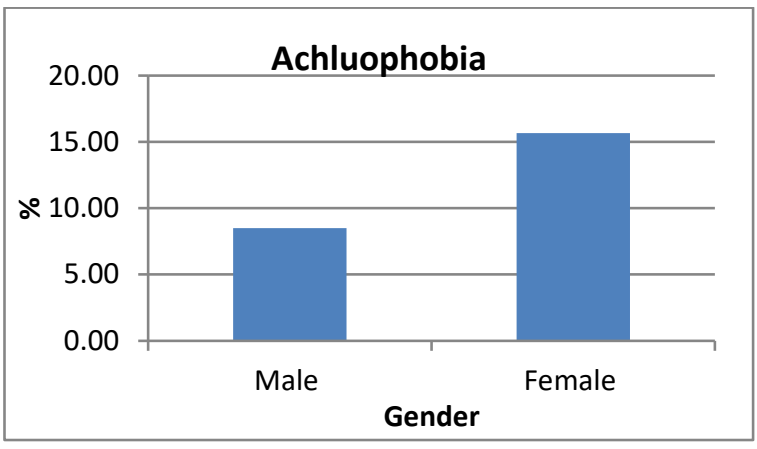

(d)

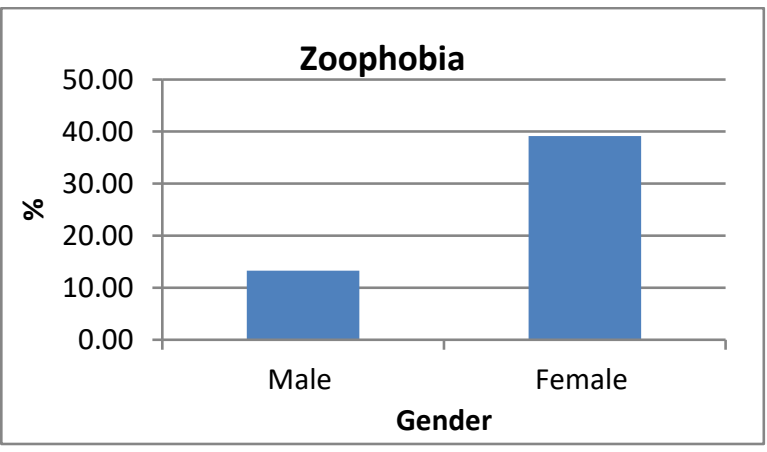

(f)

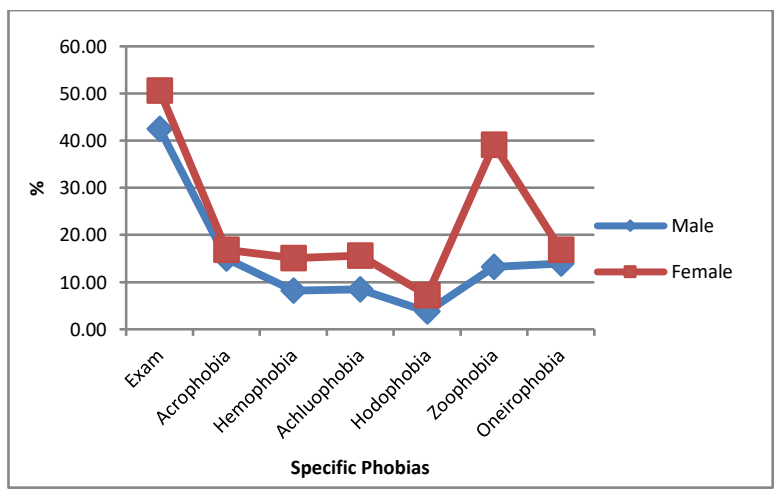

Figure 2.Comparison of Phobias and Gender

neurobiological level, significant advances have been made in identifying fear circuits and mechanisms; dysfunctions in these 
circuits/mechanisms can lead to chronic psychiatric disorders, Indeed, available treatments that aim to reduce pathological fear are associated with decreased symptom severity, but up to $40 \%$ of patients show only partial long-term benefit, while most of them fail to achieve complete remission (Singewald et al. 2015). It appears that the amygdala is central to two phenomena that may support pathological innate fear: fear sensitization (Garcia, 2017).

The treatments vary with the type of phobia. For example Exam phobia is better prevented than treated. A systematic, persistent, organized, planned and regular effort from the beginning of the academic session is the best method for any adolescent to prevent anxiety related to the examination. Students may be given frequent tests and a healthy competitive environment among their students within the class may be promoted. In case of Achluophobia and Zoophobia treatment exposures, reduce the fear.

According to Hanies et al., (2007), Cognitive Behavioral Therapy (CBT) has been found to significantly decrease phobic symptoms by helping the phobia sufferer change his or her way of thinking. A variety of treatment options are available, including Cognitive Behavioral Therapy (CBT), Exposure Therapy, Anxiety Management, Relaxation Techniques, and Medications. Hoffman and Weghorst (1997) stated that one or a combination of these may be recommended according to the situation and intensity. No any single treatment is sufficient. If anyone may be suitable for one person, perhaps it may not be the best choice for someone else.

\section{Some of the useful methods}

Exposure-based therapy - (Singh and Singh, 2016) Cognitive therapy (CT)- (Specific phobia. http://www. med.upenn.edu). Progressive desensitization (Specific phobia. http://www. med.upenn.edu). Relaxation- (Specific phobia. http://www. med.upenn.edu). Hypnosis (hypnotherapy)- (Natural treatment for phobia and anxiety. http://www.phobicss- ociety.org) Homeopathy- (http:// www.phobicssociety.org) Herbal remedies- (Natural treatment for phobia and anxiety. http:// www.phobicssociety.org). Pharmacotherapy-(Specific phobia. http:// www. med .upenn.edu).

\section{CONCLUSION}

Specific phobias influence health and academic achievement of the students. The study observed that exam phobia is high in both male $(42.52 \%)$ and female $(50.60 \%)$ students. It is concluded that the specific phobias are more in female compared to male.

\section{REFERENCES}

[1]. American Psychiatric Association (2013) Diagnostic and Statistical Manual of Mental Disorders (5th ed.), Arlington: American Psychiatric Publishing, 190, pp.197-202.

[2]. Carleton R. Nicholas (2016) Fear of the unknown: One fear to rule them all? Journal of Anxiety Disorders, 41, pp.5-21.

[3]. Curtis G C, Magee W J, Eaton WW, Wittchen H U and Kessler RC (1998) The British Journal of Psychiatry, 173:212-217.

[4]. de Oliveira-Souza R (2018) Phobia of the Supernatural: A Distinct but Poorly Recognized Specific Phobia With an Adverse 
Impact on Daily Living. Front. Psychiatry 9:590.

[5]. Fodor N, Gaynor F (2004) "Freud: Dictionary of Psychoanalysis", ISBN 0-7607-5301-6 (initial publ.1950), article "Zoophobia, infantile", pp. 205-206.

[6]. Garcia René (2017) Neurobiology of fear and specific phobias, Published by Cold Spring Harbor Laboratory Press, 24:462-471.

[7]. Hanies, J. D., Imeson, and Meade, T. W. (1987) Phobic anxiety and ischemic heart disease. Br Med J (Clin Res Ed), 295(6593): 297-299.

[8]. Hoffman, Carlin, A., H. G., and Weghorst, S. (1997) Virtual reality in the treatment of spider phobia: a case report. Behavioral Research and Therapy, 35: 153-158.

[9]. Menzies RG (1997) Height Phobia. In: Davey GLC, editor. Phobias. A Handbook of Theory, Research and Treatment. Chichester: Wiley:129-138.

[10]. Natural treatment for phobia and anxiety. Available at http:// www.phobicssociety .org.uk/naturaltreatmentforphobiaandanxiety /Accessed on 24 December 2015.onal Journal of Basic \& C.

[11]. Naveed S, Sana A, Rehman H, Qamar F, Abbas SS, et al. (2015) Prevalence and Consequences of PHOBIAS, Survey Based Study in Karachi. J Bioequiv Availab 7: 140143.

[12]. Ollendick Thomas H., Natoshia Raishevich, Thompson E. Davis III, Cristian Sirbu, LarsGöran Öst (2010) Phenomenology and Psychological Characteristics, Behavior Therapy 41, 133-141.

[13]. Pull Charles B. (2008) Recent trends in the study of specific phobias, Curr Opin Psychiatry 21:43-50.
[14]. Ronald Comer J. (2010) Abnormal psychology (7th ed.).New York:Worth Publishers, p.138.

[15]. Singewald N, Schmuckermair C, Whittle N, Holmes A, Ressler KJ. (2015) Pharmacology of cognitive enhancers for exposure-based therapy of fear, anxiety and trauma-related disorders. Pharmacol Ther 149: 150-190.

[16]. Singh Jarnail, Singh Janardhan (2016) Treatment options for the specific phobia, Vol 5, Issue 3, pp. 593-598.

[17]. Specific phobia. Available at http://www. med.upenn.edu/csta/phoias_treatment.html. Accessed on 26 December 2015.

[18]. Sufiana and Farhat (2015) Examination Phobia among Secondary Level Students, International Research Journal of Arts \& Humanities (IRJAH) Vol. 37, pp.129-146.

[19]. https://www.verywellmind.com/list-ofphobia-2795453.

[20]. https://www.medicinenet.com/script/main/ar t.asp?articlekey $=12337$.

[21]. https://www.allhealthsite.com/achluophobiadefinition-symptoms-causes-treatment.html.

\section{Cite this article as :}

SankaraPitchaiahPodila, Nazia Sultana, "Phobias and Gender - A Case Study on Engineering Students", International Journal of Scientific Research in Science and Technology (IJSRST), Online ISSN : 2395-602X, Print ISSN : 2395-6011, Volume 6 Issue 2, pp. 218-222, March-April 2019. Available at doi :

https://doi.org/10.32628/IJSRST196242 Journal URL :http://ijsrst.com/IJSRST196242 